\title{
ASSESSING THE RESPONSIBILITY TOWARDS CLIMATE CHANGE OF RESEARCH PROJECTS BY MEANS OF ANALYTIC HIERARCHY PROCESS.
}

\begin{abstract}
In this paper we aim at modeling how to assess the responsibility of research projects. For that, we focus on a specific discipline: Climate Change. We apply Analytic Hierarchy Process as the tool for analyzing the problem and engaging experts into a constructive discussion.

We believe our findings will help other researchers to identify key concepts regarding responsible research and innovation, assessing and monitoring the responsibility of research projects, starting processes of dialogue and, eventually, ranking different research proposals from the point of view of responsibility preventing climate change.
\end{abstract}

Keywords: Analytic Hierarchy Process -AHP-, Responsible Research and Innovation, Indicators, Climate Change.

\section{Introduction}

Responsible Research and Innovation has been defined as: 'a transparent, interactive process by which societal actors and innovators become mutually responsive to each other with a view on the (ethical) acceptability, sustainability and societal desirability of the innovation process and its marketable products' (Strand et al. 2015). Currently, the European Union is engaged in developing a framework, the procedures and the indicators for assessing, promoting and monitoring Responsible Research and Innovation. Such assessment and promotion should be based, on the one hand, on soft rules and relative perceptions; and on the other hand, it should be based on discussion about available alternatives or proposals. In this context, our research aims at helping understanding better what RRI is, how to engage into such a dialogue about the responsibility of research and how to start a bottom-up process of RRI assessment (Strand et al. 2015).

\section{Literature Review}

Despite the interest EU is showing, there are still scarce publications about how to assess and monitor RRI. Besides the report from the expert group on policy indicators for RRI (Strand et al. 2015), few other papers and handbooks were found as reference to our particular research on sustainable energy development research (Köppl et al. 2011; Kettner et al. 2012; Kettner et al. 2014).

\section{Hypotheses/Objectives}

Based on all the above mentioned background, our research objectives are:

1. To identify the key terms of RRI towards climate change, their relationships and to build a model for RRI assessment

3. To assess the relative importance of each key term/indicator

4. To extract conclusions that can be applied to similar processes in other research disciplines. 
ISAHP Article: A Style Guide for Paper Proposals To Be Submitted to the International Symposium on the Analytic Hierarchy Process 2016, London, U.K.

\section{Research Design/Methodology}

As it can be seen in Figure 1, the methodology is based on the work of two main actors, the research team (AHP facilitators) and a panel of experts on climate change and social responsibility.

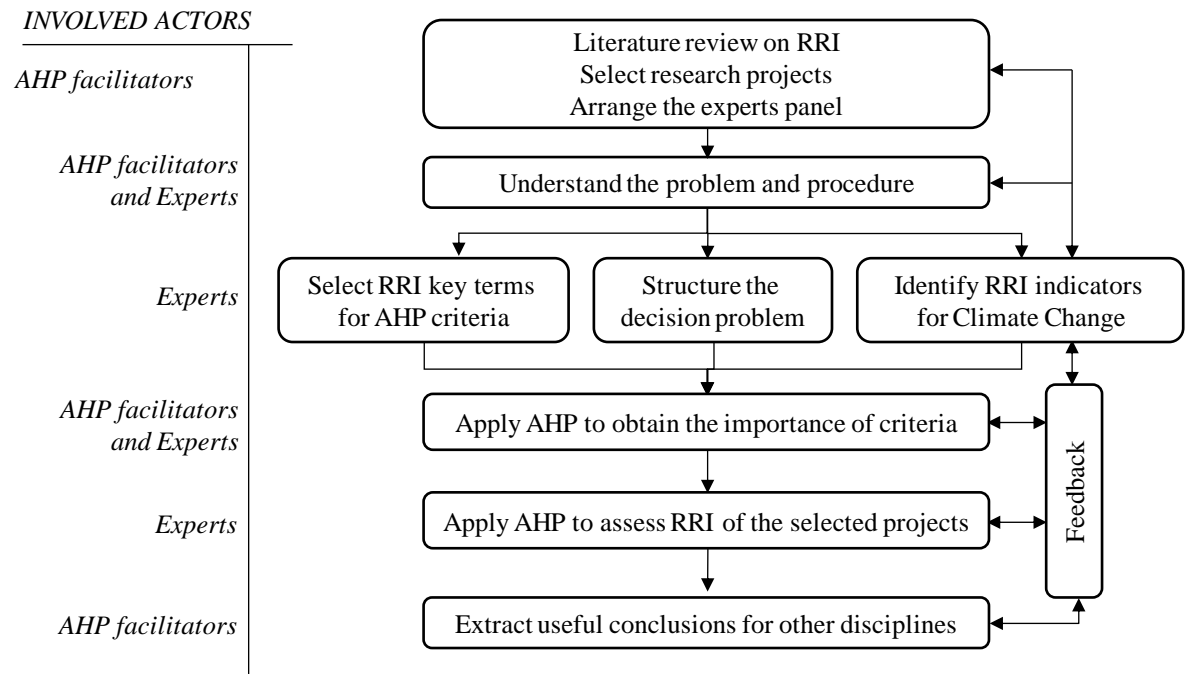

Figure 1. Research methodology

\section{Conclusions}

We have arranged the RRI criteria based on the proposal by Strand et al. (2015), with the clusters: Process, Outcomes and Perception. Besides we have taken into account monitoring all the key terms for assessing RRI: Stocks, Flow, Stock-flow interactions, etc. Indicators for monitoring the key terms were selected and some of the most important ones are: ' $\mathrm{CO}_{2}$ releases', 'Selection of low carbon alternatives', 'Measures to counterbalance Climate Change consequences', etc. Other conclusions are AHP allows making possible bottom-up processes, and indicator sets should be made to avoid unintended consequences of monitoring like: 'colonization', 'distraction from the real thing' and 'decoupling perception and performance'.

\section{Key References}

Kettner, C., Köpple, A. and Stagl, S. (2014). Towards an operational measurement of socio-ecological performance - Working paper No 52, WWWfor Europe. Available at: http://www.foreurope.eu

Strand, R., Spaapen, J., et al. (2015). Indicators for promoting and monitoring Responsible Research and Innovation. Directorate-General for Research and Innovation. Available at: http://ec.europa.eu

Kettner, C., A. Köppl and K. Köberl, (2012), The PASHMINA Indicators for Sustainable Energy Development - How Does the EU Perform? WIFO Monographs 11/2012

Köppl, A., et al. (2011), EnergyTransition 2012/2020/2050. Strategies for the Transition to Low Energy and Low Emission Structures. WIFO Monographs 2/2011. 